\title{
REPERCUSIONES FILOSÓFICAS DE LA CRÍTICA DE MARSHALL SAHLINS AL ARQUETIPO HUMANO PRO- PUGNADO POR LA COSMOVISIÓN OCCIDENTAL
}

Philosophical Repercussions of Marshall Sahlins' Critique of the Human Archetype Advocated by the Western Cosmology

\author{
Albert Muñoz Miralles \\ Universitat Jaume I \\ albertmumi@yahoo.es
}

\begin{abstract}
Resumen:
Sahlins sostiene que la autocomprensión occidental ha girado en torno a la figura del homo economicus, manifestación de una pretendida naturaleza humana universal, ocultando así su origen cultural y particular, mientras restringía otras posibles perspectivas acerca del ser humano y la sociedad. Las tendencias económicas y políticas actuales promueven un retorno de una concepción individualista, que requiere ser afrontada desde la ética, debido a sus implicaciones sociales y morales. Se pretende así evaluar las aportaciones que ofrezca el planteamiento de Sahlins para una consideración crítica de las actuales dinámicas económicas y de su soporte ideológico, sostenida en una comprensión del ser humano orientada éticamente.
\end{abstract}

Palabras clave:

Homo economicus, Sahlins, capitalismo, individualismo.

\begin{abstract}
:
Sahlins argues that western self-understanding has revolved around the figure of homo economicus, a manifestation of a supposed universal human nature, thus hiding its cultural and particular origin, while restricting other possible perspectives about the human being and society. The current economic and political tendencies promote a return of an individualistic conception, which needs to be confroncted from ethics, due to its social and moral implications. The aim is to evaluate the contributions offered bu Sahlin's approach to a critical consideration of current economic dynamics and their ideological support, based on an ethically oriented understanding of the human being.
\end{abstract}

Keywords:

Homo Economicus, Sahlins, Capitalism, Individualism.

Recibido: 10/05/2019

Aceptado: 21/06/2019 
Repercusiones filosóficas de la crítica de Marshall Sahlins al arquetipo humano propugnado por la cosmovisión occidental

\section{INTRODUCCIÓN}

La reflexión acerca de la actividad económica ha estado dominada en buena medida por una línea de pensamiento que tiende a considerarla como un campo de acción determinante para el conjunto la vida social, que obedece a una pretensión de maximización racional del interés particular de cada agente. Pero esa comprensión se asienta, necesariamente, sobre una serie de asunciones sobre la naturaleza humana y la sociedad, que son susceptibles de crítica. De hecho, pese a la vigencia de ese pensamiento ortodoxo de la economía, no han sido pocos los intentos que han tratado de poner en cuestión tanto los principios en los que se sustenta como sus implicaciones. Aunque sería un error reducir el pensamiento económico a un modelo determinado, abarcando perspectivas abiertamente enfrentadas a los principios del liberalismo económico, y en particular a la idea del agente maximizador, sigue siendo evidente la influencia de esa concepción economicista de lo social. De hecho, las orientaciones que dirigen la economía globalizada de nuestro tiempo parecen propugnar un retorno de aquellos planteamientos, resituando la problemática planteada en unas nuevas coordenadas, por lo que se trataría de un debate todavía abierto.

La asunción generalizada de una determinada concepción antropológica y de la sociedad tiene importantes efectos sociales y personales, ya que permite justificar o promover la adopción de determinadas políticas o líneas de actuación institucionales, además de alentar ciertos patrones de comportamiento y elección en los individuos y en los grupos. Se trata de cuestiones que apelan intrínsecamente a la reflexión ética, desde la que se puede trazar una definición del ser humano que sirva como instancia crítica para valorar los modelos humanos y sociales que se promueven desde el ámbito institucional o desde las ciencias. Ya que según se pretende sostener aquí, para alcanzar una comprensión ajustada del ser humano es imprescindible acudir a la mirada crítica que ofrece la ética, entendida como una forma de saber normativa, aunque abierta a las aportaciones que se realizan desde los distintos ámbitos del saber que abordan la compleja realidad humana.

Por ello, es importante dilucidar cuáles son los sustentos históricos y culturales que han permitido la conformación y la revitalización de esa tendencia ideológica que condiciona de manera tan amplia y profunda las practicas institucionales y las acciones sociales en el mundo actual.

Para ese propósito, las aportaciones del antropólogo Marshall Sahlins ofrecen una especial relevancia, pues permite considerar la particularidad de la ideología dominante en occidente a través de un distanciamiento respecto a nuestra propia tradición cultural que abre la puerta a una mirada autorreflexiva y crítica sobre sus propios fundamentos. Sin embargo, deberán afrontarse las limitaciones que pueda presentar tal planteamiento teórico, especialmente a la hora de configurar una propuesta crítica capaz de responder adecuadamente a los complejos retos, tanto teóricos como prácticos, que plantea la actualidad, atendiendo a sus implicaciones morales.

Se seguirán los siguientes pasos: en primer lugar, se mostrará cómo la implantación de una comprensión economicista de la vida social en occidente implica una determinada visión del ser humano, que resulta altamente controvertida, siendo objeto de diversas líneas de cuestionamiento. Entre ellas, cabe destacar la argumentación de 
Sahlins, que pretende dirigirse a las bases culturales de la configuración institucional típicamente moderna, para revelar su carácter ideológico. Seguidamente, pues, se tratará de presentar los aspectos definitorios de la ideología occidental, que coforma una descripción peculiar del ser humano, como un ser finito sumido en un estado de carencia permanente, dando razón de ser al establecimiento de una configuración institucional subordinada a lo económico. A partir de ahí, se establece una relación conflictiva entre la supuesta naturaleza encarnada en los individuos y una sociedad conformada artificialmente, que marca el devenir del pensamiento occidental. En el siguiente apartado, no obstante, se cuestionará la idea asumida de una singularidad occidental, intensificada por el desarrollo histórico de una forma de economía capitalista. Sahlins pretende contemplar las diferentes formas de vida desde una comprensión simbólica de lo cultural, que permitiría acercarse de nuevo a nuestra propia sociedad con una perspectiva más amplia, dejando atrás los prejuicios materialistas. Finalmente, se propondrá una valoración sobre el modelo humano y social que ofrece Sahlins desde una perspectiva ética, tratando de afrontar sus posibles debilidades y sobre todo aprovechar su potencialidad para afrontar los retos que plantea el complejo mundo globalizado de nuestros días.

\section{EL CUESTIONAMIENTO DE LOS POSTULADOS DE LA ECONOMÍA MODERNA}

Los procesos asociados a la modernización occidental produjeron una escisión de la vida social en ámbitos funcionales diferenciados y relativamente autónomos, aunque sometidos a una primacía de lo económico (Sahlins, 1988a: 209-210). El mercado se convirtió en la institución determinante de la sociedad (Polany, 2001: 105). Es decir, si bien el funcionamiento de las diversas instituciones se torna más complejo, tiende a obedecer a una lógica común, la eficacia, que ha de plasmarse en la racionalización de todos los aspectos de la vida social. El dominio de una visión economicista propició la asimilación de un determinado modelo humano, encarnado en la figura del homo economicus (Conill, 2004: 114 ss.); percibido como "a logical thinker who evaluates options and inputs consistently and coherently, and selects those that maximise his utility" (Ortiz, 2005: 63). Su asimilación general supuso una ruptura con las concepciones tradicionales sobre el ser humano, con los modelos de integración social heredados y con la moral.

La ciencia económica desempeña, sin duda, un papel clave a la hora de dar carta de naturaleza a las concepciones modernas sobre el individuo y la sociedad. La economía neoclásica, sirviéndose de un individualismo metodológico, aísla la acción económica del contexto social e institucional postulando la universalidad de la maximización de la utilidad subjetiva, y subestimando las variables no-económicas, culminando lógicamente en una teoría general del comportamiento humano (Lie, 2004: 220). Pero el homo economicus podía funcionar como paradigma general de la acción social en tanto se aceptara que la racionalidad económica ofrecía el patrón elemental de cualquier forma de conducta. Se daba a entender, de este modo, que la descripción del comportamiento habitual de los individuos no se restringe al ámbito de la interacción económica, y que no se trata meramente de una expresión histórica o cultural determinada, y por tanto relativa, en la medida en que se apela a una supuesta naturaleza humana. Este será, precisamente, el espacio donde encajaran diferentes críticas 
Repercusiones filosóficas de la crítica de Marshall Sahlins al arquetipo humano propugnado por la cosmovisión occidental

procedentes de la antropología, o de perspectivas económicas o sociológicas alternativas ${ }^{1}$. Pero también la ética ha tenido que ir reajustando su mirada ante una actividad económica liberada de las ligazones morales tradicionales (Conill, 2004: 120 ss.).

De manera general, pues, se trataría de poner de manifiesto la incapacidad de un esquema economicista para dar razón de la conducta real que muestran las personas, influenciada por una amplia gama de incentivos y motivaciones (Anderson, 2000: 173; Sen, 1977). Por ello, su capacidad predictiva sería más endeble de lo que pretende, revelando deficiencias en el trabajo empírico (Goudy, 2006: 96). Pese a la confianza de la teoría estándar en un modelo mecanicista para explicar la interacción económica, ésta es realizada por unos agentes que disponen de una constitución psicológica, social y moral muy compleja, que establece los límites, posibilidades y orientación de cualquier tipo de relación de la que participen ${ }^{2}$. Así, la calidad y durabilidad de una interacción puede ser potenciada por la influencia de sentimientos genuinamente pro-sociales, como la simpatía, por las tendencias cooperativas o las capacidades morales.

Diversas investigaciones llevadas a cabo en los campos de la biología evolutiva, la etología o las neurociencias, junto a estudios etnográficos o sociológicos, resaltan la importancia de los mecanismos que potencian la conexión con los otros. La imagen del hombre económico sería desafiada, de este modo, por la figura de un homo reciprocans, incidiendo en la poderosa influencia que en la conducta manifiestan las capacidades intrínsecas de los humanos para la reciprocidad y el altruismo -existiría una estructura moral universal, la reciprocidad fuerte- (Fehr y Fisbacher, 2003; Gintis et. al., 2008); o bien por la de un homo sociologicus, afirmando que la acción social no puede entenderse desde una perspectiva meramente instrumental, pues responde primariamente a la autocomprensión que se forman los individuos como parte de los grupos sociales y al cumplimiento de unas normas con cuya autoridad se comprometen (Anderson, 2000: 191 ss.). Las personas conceden importancia a la pertenencia a colectividades, reconociendo una serie de valores y propósitos comunes que trascienden las relaciones mercantiles y el interés privado.

El carácter restrictivo de la concepción humana que pone en juego el modelo predominante en la economía se hace patente más agudamente cuando se alza una perspectiva ética. La idea de un ser humano movido perentoriamente por el interés crematístico, y la comprensión de la interacción social desde la óptica del cálculo instrumental, implica el menosprecio de la autonomía moral como capacidad humana fundamental, obviando la importancia de las consideraciones morales para motivar la acción. Pero la ciencia económica se constituyó como un saber técnico, ajustado a las

\footnotetext{
${ }^{1}$ En el ámbito de la economía, cabe destacar entre los enfoques planteados como alternativa a la escuela neoclásica y el modelo de elección racional, junto a la tradición marxista, a autores clásicos como Veblen, Keynes o Galbraith, o más recientes como Sen o Zagmani.

${ }^{2}$ La explicación general de la interacción en un modelo mecanicista, típico en la economía estándar, presenta a los agentes como seres que meramente responden a los incentivos a través del cálculo, impidiendo así su reconocimiento como sujetos autónomos (Conill, 2004: 117).
} 
exigencias de racionalización que impone el predominio del mercado, desprendiéndose de los restos morales que la dotaban de sentido (Conill, 2004: 122).

Sin embargo, cabría cuestionarse si estas críticas habituales permiten acceder al fondo de la cuestión o se limitan a jugar en el mismo terreno que dispone la economía moderna, proponiendo simplemente unas percepciones alternativas acerca de la realidad humana. Se trataría de explorar si es posible alumbrar una crítica más radical, es decir, que se dirija a la raíz, al origen mismo de la concepción dominante. Así, se pretende dilucidar hasta qué punto las investigaciones de Sahlins permiten cumplir satisfactoriamente tal propósito, guiado por una brújula éticamente orientada.

Sahlins cuestiona la necesidad de partir ineludiblemente de una concepción de la naturaleza humana, evitando así enzarzarse en discusiones acerca de cómo somos o cómo nos comportamos realmente los seres humanos. Pues se trataría, justamente, de desvelar el cariz ideológico, cultural y relativo de los discursos que se generan sobre lo humano y lo social, y que se emplean para justificar determinados entramados institucionales y patrones de actuación. De este modo, se revelaría que la pretendida universalidad de sus principios y valores es tan relativa e histórica como cualquier otro sistema de pensamiento. Pues se trata de una cosmovisión -cosmology-, la visión particular del mundo y de la humanidad que propugna la sociedad occidental, manifestando realmente, por tanto, una forma determinada de autocomprensión (Sahlins, 2011: 19-22). Sin embargo, como se verá, el propósito del autor corre el riesgo de verse atrapado por sus propias pretensiones. Es decir, habrá que esclarecer si la definición del ser humano que propone no se halla a su vez marcada por una influencia restrictiva de los factores culturales. Por ello es preciso reivindicar la función de la ética, cuestionando la justicia o legitimidad de los principios y valores sobre los que se asientan los sistemas sociales o culturales, ofreciendo una imagen del ser humano no reducible a sus bases biológicas o socio-culturales.

Como puede ya apreciarse, Sahlins se opone a las concepciones materialistas, que convierten a la esfera cultural en mera superestructura condicionada por la infraestructura material, por el modo de producción (Sahlins, 1988b: 3). A partir de ahí, se trataría de resituar el papel y la función de lo económico en el entramado socio-cultural, tarea que encuentra sus puntos de apoyo en autores como Polanyi o Dumont. Una antropología económica pretende entender la vida económica en términos más amplios, situándola en el contexto del mundo social y cultural en que se insertan las diversas prácticas y creencias vinculadas (Carrier, 2005: 4) Cabría así cuestionar los postulados de la economía moderna, contemplados no sólo como soporte justificativo de la actividad económica, sino como el fundamento ideológico de una forma de acción, de configuración institucional y de una estructura de saber.

La cuestión clave, por tanto, es si tal planteamiento, que obedece al propósito de clarificar las bases culturales distintivas, puede representar una perspectiva que aporte una mayor carga crítica respecto a los supuestos que sostienen el funcionamiento de la sociedad moderna, en la que lo económico se revela como la esfera axial. Por ello, habrá que precisar cómo se establece la peculiaridad occidental, y determinar en qué medida su autocomprensión economicista puede oscurecer la comprensión de otras realidades culturales, y a la postre, también de sí misma. 
Repercusiones filosóficas de la crítica de Marshall Sahlins al arquetipo humano propugnado por la cosmovisión occidental

Sahlins pretende superar la idea generalizada de que las culturas se articulan en torno a intereses utilitarios, o que obedecen a necesidades adaptativas, para reforzar la idea de la cultura como un orden simbólico autónomo, es decir, no subordinada a determinaciones externas, sino generadora de realidad por sí misma y mediadora de la relación de sus miembros con el entorno (Sahlins, 1988a: 9-11 y 61). Sin embargo, el pensamiento social habría afianzado una visión instrumental de la cultura, contemplándola como un medio dirigido a la satisfacción de ciertas necesidades previas, impuestas por la naturaleza ${ }^{3}$. Sahlins denuncia así que la antropología se entregó a dos tipos de naturalismo: el ecologismo de la ventaja selectiva, que respondería a la lógica adaptativa, referida a una naturaleza externa; y el economicista que remite a una supuesta naturaleza humana, la del individuo racionalizador (id.: 88 y 105). Para explicar la conducta rea/de los individuos sería, preciso, pues, atender a sus motivaciones e intereses cuyo origen habría que explorar por debajo de la configuración establecida por la cultura, apuntando a la naturaleza.

Esta denuncia de Sahlins permite elaborar, a mi juicio, tres propósitos complementarios: por un lado, abre el camino a una deconstrucción del concepto particular que de la naturaleza se ha forjado en la cultura occidental a través de los discursos producidos desde distintos ámbitos especializados del saber -biología, economía, economía política, antropología, etc.-. Su concreción más representativa se habría realizado, precisamente, en la figura del homo economicus. En segundo lugar, permitiría redefinir la visión que mantiene occidente respecto a las culturas ajenas. Finalmente, se trataría de sostener una concepción general de la cultura que permita rebatir la comprensión instrumental de la misma, incidiendo en su carácter autónomo subrayando el predominio de una lógica propia, la simbólica. Este propósito sería compartido por otros antropólogos como Clifford Geertz, Mary Douglas, o más recientemente Daniel Miller.

De este modo, se invertiría la relación de los términos que Sahlins atribuye al naturalismo, pues desde la posición que pretende reforzar, se revelaría que es la propia cultura la que organiza la actividad material de una sociedad, la que ordena la relación con la naturaleza, y la que define los intereses y motivaciones que guían las decisiones y acciones de sus miembros (id.: 204-207).

Según pretende destacarse aquí, la argumentación de Sahlins aporta una nueva luz en la comprensión del capitalismo, que configura un tipo específico de sociedad alrededor de sus principios y su dinámica, desvelándose como una potente maquinaria productora y reproductora de significado social. Sahlins imprime, a mi entender, una comprensión hermenéutica del tipo de sociedad que se articula en torno al mercado, para demostrar, eso sí, que no son unas necesidades o intereses materiales independientes los que determinan su existencia, sino que éstos son más bien el resultado de una configuración cultural específica. No es en definitiva, desde este punto de vista, la infraestructura la que determina la conformación de la superestructura, tal como se ha asumido incluso en buena parte de la investigación antropológica. Pues es más bien la cultura la que dota de significado a una forma de economía.

\footnotetext{
${ }^{3}$ Especialmente significativo es el funcionalismo de Malinowski. Cfr. Sahlins (1976: 78 ss).
} 


\section{LA IDEOLOGÍA OCCIDENTAL: EL SER HUMANO COMO UN INDIVIDUO PRECARIO}

La conformación de un determinado sistema de producción e intercambio -que comúnmente se designa como capitalista- respondería, según Sahlins, a una forma específica de interpretar las necesidades humanas, que es fruto a su vez de una concepción antropológica particular, elaborada dentro de la tradición de pensamiento occidental desde una raigambre religiosa. Encuentra en San Agustín la expresión ya definida de una concepción pesimista acerca de la condición humana que marcará el desarrollo de la cultura occidental. El ser humano se define así como un ser intrínsecamente finito y corruptible, fruto de la caída, morador de un mundo creado ex nihilo y, por tanto, ajeno a la naturaleza divina. En la finitud humana se hallaría la raíz del mal (Sahlins, 2011: 67-68). Se trata de una criatura atada a la necesidad, abocada a vivir en un estado de permanente carencia, arrastrada por el deseo en su búsqueda incesante de lo placentero, evitando lo doloroso, pero cuyos anhelos nunca podrán ser plenamente consumados en un mundo que inevitablemente resulta insatisfactorio. En esta descripción podrían reconocerse ya, sugiere Sahlins, los trazos principales del prototipo del hombre económico (Sahlins, 1996: 396-397).

El desencantamiento del mundo natural, resultado de su radical distinción respecto a lo divino, permite objetivizarlo, poniéndose a disposición de la satisfacción de las aspiraciones humanas. En esta situación, la función de la economía adquiere plena razón de ser, entendiéndose como el saber adecuado para aprovechar los medios escasos que proporciona la naturaleza para satisfacer las inextinguibles necesidades humanas, paliando así la situación de carencia primigenia (id.: 397 y 411). Pero lo que San Agustín consideraba aún como una forma de esclavitud, la evolución del pensamiento moderno lo transformará en el soporte de la libertad, naturalizando las necesidades, de manera que la búsqueda de sensaciones placenteras y de la consecuente evitación del dolor se podrá interpretar más bien, en el nuevo marco burgués, como la legítima expresión de las aspiraciones individuales, incluso en fuente de virtud. En la versión burguesa de la cosmología cristiana, liberando la búsqueda del placer de la carga del pecado, la libre voluntad es trasmutada en elección racional, expresión de la preferencia individual (Sahlins, 1988b: 44; 1996: 397-398; 2011: 82). Según había ya percibido Hirschmann, la culminación del proceso de emancipación de la economía moderna respecto a sus anclajes sociales y políticos tradicionales requería de un cambio valorativo que permitiera legitimar la prosecución del interés personal como móvil fundamental de la acción social. Si en la moral pre-moderna el afán de lucro y las actividades comerciales eran contempladas con desconfianza, la modernidad alumbró una atmósfera más tolerante, Ilegando a celebrar sus efectos positivos (Hirschman, 2014: 33-37 y 70-78).

La definición de hombre económico que ofrece Sahlins descansa, no obstante, sobre el supuesto de una continuidad fundamental de la tradición occidental, pudiendo afirmar que "The Economic Man of modern times was still Adam. Indeed, the same scarcity-driven creature of need survived long enough to become the main protagonist of all the human sciences" (Sahlins, 1996: 397). Es decir, se trata de una figura inscrita en la médula de la cultura occidental, otorgándole un sello propio y peculiar. Pues, añade Applbaum, esa ideología liberal-burguesa está incorporada no sólo en los esquemas clasificatorios y motivacionales dominantes, ya que se realiza y encarna en 
Repercusiones filosóficas de la crítica de Marshall Sahlins al arquetipo humano propugnado por la cosmovisión occidental

las prácticas cotidianas reconocibles en la sociedad (Applbum, 1998: 324). Pero así, su asimilación popular, lejos de ser espontánea, habría requerido de un esfuerzo intelectual continuado, durante el cual se habría producido una evolución que, sin alterar sus rasgos fundamentales, acentuó la orientación economicista que caracteriza a la modernidad.

Las nuevas formas de saber son las que dan forma definida a este proceso interno de transformación. Particularmente la economía, establecida como ciencia positiva, normaliza la racionalidad utilitaria como forma de optimizar el proceso de asignación de recursos para maximizar la satisfacción de las preferencias individuales (Sahlins, 1988a: 167). Por eso, el mercado se presenta como la solución práctica al problema perpetuo de las necesidades (Applbum, 1998: 326). Sin embargo, a través del entramado de la economía capitalista se produce una fetichización de las necesidades, atribuyendo un origen meramente fisiológico al deseo, se trata como una experiencia subjetiva, ocultando que realmente es el producto de una determinada configuración social (Sahlins, 1996: 401; 2011: 202) ${ }^{4}$. Por ello, el hombre económico aparece como un ser universal, como la expresión ajustada de una naturaleza humana aparentemente autónoma respecto del marco socio-cultural (Sahlins, 1976: 105) .

Aunque conviene precisar de nuevo, frente a la descripción un tanto reduccionista que ofrece Sahlins, que dentro de la ciencia económica existen propuestas destacadas que no se constituyen sobre las premisas del individuo maximizador y del atomismo social. Y que tampoco el funcionamiento del capitalismo corresponde a un esquema invariable, ya que pueden reconocerse diferentes modalidades históricas o regionales (Crouch, 2005). Si bien, lo importante es que en determinados momentos la concepción que Sahlins identifica como idiosincrática de occidente, ha adquirido una posición predominante, dirigiendo la orientación de las políticas y modelando la mentalidad de la gente. El actual marco de la nueva economía globalizada, caracterizado por la flexibilización organizativa y la precarización laboral, facilitaría la revitalización de una ideología marcadamente individualista (Muñoz, 2014: Capítulo 7).

El aspecto quizá más trascendente de tal concepción antropológica es que su reconocimiento del individuo auto-interesado como representante y fin último de la humanidad, normaliza una visión utilitarista de la sociedad y de la cultura. Pues, desde esta perspectiva, "la sociedad es el conjunto de las relaciones empíricamente constituidas por la búsqueda de intereses privados con los medios de que se disponga" (Sah-

\footnotetext{
${ }^{4}$ Sahlins observa las dificultades de Marx para precisar el concepto de "necesidad", ya que en tanto se realiza a través de la mercancía como valor de uso remitiría a su origen biológico primario, aunque cumple también una función que es asignada socialmente. En otros momentos, la concebiría como un producto histórico, y el proceso de producción capitalista como un modo de vida particular, no ya como mera reproducción de la vida, abriendo la posibilidad de una interpretación simbólica de la formación de las necesidades, tarea que trascendería los límites de la economía política (Sahlins, 1988a: 150 ss.).

${ }^{5}$ El recurso a la teoría de la elección racional permitía hacer comprensible, a ojos de un observador occidental, los comportamientos aparentemente irracionales de los miembros de otras sociedades (Sahlins, 2013: 185-186).
} 
lins, 1976: 58). Como resultado, la sustancialidad del la sociedad se desvanece, concebida simplemente como un instrumento susceptible de ponerse al servicio de la satisfacción las necesidades fisiológicas de los individuos (Sahlins, 1990:128 ss.; 1996: 401). Se trataría, por tanto, de un orden derivado, constituido para lograr un cumplimiento más efectivo de los intereses particulares enfrentados, de modo que las reglas sociales y principios morales se imponen como coerciones externas para contener las tendencias egoístas naturales. Las inclinaciones naturales, pues, serían las que orientan y otorgan sentido a las instituciones sociales, como paradigmáticamente sucede con la economía (Sahlins, 2011). El fundamento de las instituciones modernas deja de localizarse así en la esfera de lo sagrado para invocar otros fuentes generativas, fundamentalmente la naturaleza. Esa idea de la sociedad como un orden natural creado por agentes autónomos auto-interesados, cuya razón de ser radica en la satisfacción de las necesidades individuales, fue plenamente asumida por la economía del siglo XX (Goudy, 2006: 89).

La desintegración de la sociabilidad deja el camino libre a un individualismo posesivo, de modo que el individuo es "es visto como esencialmente como propietario de su propia persona o de sus capacidades sin que deba nada a la sociedad por ellas" (Macpherson, 2005: 15). Pero esa descripción, aseguraba Macpherson, no es más que una transposición de la sociedad burguesa -la sociedad posesiva de mercado- que estaba alumbrando la modernidad, otorgando carta de naturaleza al predominio creciente de las relaciones mercantiles. Sahlins incide, precisamente, en el carácter ideológico y relativo de dicha comprensión de lo social, idiosincrásica de la modernidad occidental, articulada históricamente a través de la oposición entre naturaleza y cultura.

Se han ido así construyendo una serie de discursos y elaboraciones teóricas sustentados en una idea de la naturaleza humana refractaria a la sociabilidad, reforzando los postulados de la autonomía individual. Desde este punto de partida, la tensión entre individuo y sociedad se torna inevitable, dando lugar a una pugna perpetua que amenaza con disolver los frágiles vínculos sobre los que se asienta la convivencia. La acción humana se concibe así marcada desde el nivel biológico, donde se hallarían un conjunto de disposiciones innatas que indican la familiaridad con el reino animal, condicionando inevitablemente la práctica cultural (Sahlins, 1996: 400). Se trata de una concepción firmemente enraizada en el pensamiento europeo, reconocible en la clásica distinción physis/nomos, aunque reformulada por la modernidad. La cultura quedaba inevitablemente equiparada a lo convencional y lo artificial, mientras se asumía que es la naturaleza la que contiene el auténtico ser de la humanidad (Sahlins, 2011).

Así, a partir especialmente de Hobbes, habría ido perfilándose la imagen de una sociedad constituida artificialmente sobre vínculos de interés entre criaturas que naturalmente tienden hacia la búsqueda de su propio bienestar. La descripción del comportamiento humano debía realizarse conforme al principio del realismo, es decir, haciéndose cargo de la inmoralidad subyacente, de la inevitable conflictividad intersubjetiva. Por ello, la sociedad política se consideraba como el necesario sistema de con- 
Repercusiones filosóficas de la crítica de Marshall Sahlins al arquetipo humano propugnado por la cosmovisión occidental

troles y salvaguardas para encauzar la competencia (Sahlins, 2011: 31 y 89). Asumiéndose que su resolución ha de conducir, automáticamente, al establecimiento de una economía de mercado (Sahlins, 1990: 123 ss.).

Esta visión descarnada de la sociedad es fácilmente reconocible en un pensamiento economicista que tiende a presentar la competencia entre seres particulares movidos por el auto-interés como un fenómeno natural, obteniendo de la biología -especialmente del enfoque sociobiológico- un estimable semblante de cientificidad, que permite camuflar su raíz ideológica. En este sentido, denuncia Sahlins que se haya ido imponiendo paulatinamente una relectura forzada del concepto de selección natural, ajustada a la metáfora del individuo emprendedor actuando en un mercado competitivo, representada en la idea de la auto-maximización genética (Sahlins, 1990: 32 ss.). En definitiva, la retroalimentación entre determinadas corrientes de la biología y de pensamiento político-económico contribuyó decisivamente a normalizar la perspectiva del individualismo posesivo, que invita a contemplar el individuo como el homo economicus cuya acción tiende a la maximización, y a la sociedad meramente como el conjunto de relaciones de intercambio, donde nunca llega a cancelarse la originaria naturaleza egoísta de sus miembros (id.: 129 ss.).

Habría que matizar, no obstante, que si bien durante unos años el impacto de la sociobiología -siendo Wilson el objetivo predilecto de las críticas de Sahlins al biologismo- o de propuestas como la de Dawkins fue muy notable, aproximando la ciencia natural a la concepción de lo social radicalizada del capitalismo más competitivo -por aquel entonces la entrada en crisis del modelo social del bienestar propició la implementación de las políticas neoliberales-, desde entonces numerosas investigaciones han enfatizado la importancia de las tendencias prosociales, reconocibles ya en especies emparentadas con la humana ${ }^{6}$. Cabe señalar que el propio Wilson habría moderado sus posiciones iniciales, pasando a defender la influencia de la selección de grupo, dentro de un modelo multinivel, o la tesis de la co-evolución gen-cultura, incorporando los avances en epigenética (Wilson, 2012). No obstante, parecería mantenerse aferrado a una comprensión de lo humano fuertemente condicionada desde el nivel biológico, reconocible a su vez en la ambigua imagen que actualmente proyectan las neurociencias. Éstas enfatizan la persistencia de respuestas marcadamente emocionales favorables a los miembros del grupo, y a la vez, de desconfianza u hostilidad hacia los extraños, explicables a partir de la constitución arcaica de nuestra estructura neural (Cortina, 2010: 136-139).

Y de manera aguda, Hartmann desvela cómo la imagen del ser humano que conforma la neurociencia, a través de la interpretación del funcionamiento de las redes neurales, se ajusta a los requerimientos que establece la actual fase del capitalismo, reconocible por la flexibilidad y la descentralización (Hartmann, 2012: 79-82) ${ }^{7}$. Es importante recalcar que la configuración institucional de nuevo capitalismo, que di-

\footnotetext{
${ }^{6}$ Cfr. Dawkins (2002); Wilson (1980); o en favor de la prosocialidad, p. ej., los trabajos de De Waal.

7 Una aproximación estimable a las consecuencias personales y sociales del capitalismo flexible se halla en los trabajos de Richard Sennett. Cfr. Muñoz (2014).
} 
suelve las garantías y protecciones que ofrecía el modelo más inclusivo y cohesionador del capitalismo social, promueve la adopción de actitudes competitivas y oportunistas, características del retrato típico del homo economicus (Muñoz, en prensa). Se trata por ello de un escenario que, a mi juicio, otorga renovada actualidad e interés a la problemática hacia la que apunta Sahlins.

Su aproximación a la realidad humana le lleva a rechazar frontalmente cualquier intento de explicación que pretenda enraizarse en los fundamentos biológicos o naturales, pues implicaría un desplazamiento del papel esencial que, a su juicio, representa la cultura. No obstante, como se incidirá más adelante, una confianza excesiva en el poder explicativo de lo cultural corre el peligro a su vez de desembocar en otra forma de reduccionismo, en la medida en que sugiera que la acción humana se explica completamente desde sus bases culturales. Una reivindicación ajustada de la originalidad del ser humano implica situar en primer plano la dimensión moral, que permite trascender los diferentes factores biológicos, sociales o culturales que en diverso grado influyen en la acción, abriendo un espacio primordial a la libertad y al pensamiento crítico.

En cualquier caso, merece la pena profundizar en la crítica que efectúa Sahlins de las explicaciones naturalistas en tanto permite explicitar una concepción del significado que invierte la relación entre naturaleza y cultura que denuncia como elaboración ideológica particular. Así, insiste en que la propia noción de naturaleza no es sino una categoría social, que adquiere su definición, función y sentido en el marco de un determinado esquema cultural (Sahlins, 1988a: 116-117). La idea de naturaleza que habría ido configurado la tradición occidental -reconocible incluso en Marx- podría interpretarse así atinadamente como una metáfora del capitalismo (id.: 60 y 163). Es, por tanto, la expresión de la visión que una determinada sociedad se ha ido formando sobre sí misma.

\section{¿HASTA QUÉ PUNTO ES LíCITO HABLAR DE LA ORIGINALIDAD OCCIDENTAL?}

Según se ha expuesto, Sahlins atribuye el establecimiento en occidente de una determinada forma de ordenar la satisfacción de las necesidades y la organización social a la preponderancia de una ideología que respalda una concepción específica sobre el ser humano. Sin embargo, quedan algunas cuestiones abiertas, en referencia a la peculiaridad atribuida al modo de vida y el pensamiento occidental en relación con otras sociedades, sobre las que ejercería una influencia determinante. Aunque habría que preguntarse hasta qué punto esa diferenciación no es el producto, precisamente, del saber que ha ido generando nuestra tradición. Y en esa encrucijada, la antropología jugaría un papel crucial. Por otro lado, permanece la cuestión de la continuidad en la tradición occidental, precisando el alcance de la radicalidad impuesta por la modernidad.

El punto de ruptura parece hallarse en la centralidad adquirida por lo económico, convirtiéndose en el principio estructurador de la sociedad occidental moderna a través del peso adquirido por el mercado, mientras que la mayoría de sociedades estudiadas se organizarían en torno a otros principios, principalmente el parentesco (Isaac, 2005: 14; Sahlins, 1988b; 2015: 189). En ese sentido, se advierte la importancia his- 
Repercusiones filosóficas de la crítica de Marshall Sahlins al arquetipo humano propugnado por la cosmovisión occidental

tórica del proceso de autonomización del individuo, que liberándose de sus obligaciones tradicionales respecto al linaje o el grupo social, puede construirse su propia posición. La reivindicación de la propiedad privada es clave en la elaboración de la ideología individualista que legitima el ascenso de lo económico. Pues, como apreció Dumont, el surgimiento de lo económico como esfera diferenciada va unido necesariamente a un cambio de valores solidario con la aparición del individuo moderno. El paso de una sociedad tradicional, holista, a una moderna, individualista, se nutre de la introducción de una distinción que no se encuentra en el primer tipo, entre lo "político" y lo "económico", reforzada por una revolución en los valores que dará forma a la ideología moderna, centrada en el individuo y acorde con la primacía económica. Un aspecto crucial reside en una traslación en la primacía de las relaciones entre los hombres -característica de la sociedad tradicional- a la relación que el hombre, como individuo, mantiene con las cosas, a través de la institución de la propiedad (Dumont, 1999: 16 y 134-135). No obstante, según se ha señalado, Sahlins sitúa las raíces de esa ideología economicista en el los fundamentos judeo-cristianos de la tradición occidental, subrayando su continuidad. En cualquier caso, parece claro que esas semillas habrían germinado plenamente con el advenimiento de la modernidad, marcando un punto de no retorno respecto a la ordenación tradicional de la sociedad.

Weber otorga una importante influencia a las ideas dentro de una comprensión plurifactorial en la implementación del amplio proceso de racionalización que experimentó occidente, del que forma parte fundamental el capitalismo racional. Particularmente, ciertas evoluciones del protestantismo que propiciaron el desencantamiento del mundo y el desarrollo de actitudes que se realizaban en un tipo peculiar de emprendimiento empresarial (Weber, 2001). Si bien en India o China podría reconocerse la existencia algunos de elementos estructurales, materiales o ideales proclives a la racionalización, la confluencia necesaria se había dado sólo en occidente, donde habría podido culminar esa compleja evolución (Giddens, 1992: 243-299).

Parece así haberse afianzado la idea de una diferenciación radical entre el occidente moderno y el resto de un mundo constituido sobre principios y estructuras tradicionales. La razón de ser del surgimiento de la disciplina antropológica se puede plantear, precisamente, como el intento por parte de los occidentales por comprender las otras sociedades. Pero, como observa Sahlins, esa tarea se ha desarrollado en buena medida marcada por el predominio de una perspectiva materialista y utilitarista, reflejo de un punto de vista característicamente occidental, provocando la formación de una imagen deformada de aquellas sociedades que, como reverso, dificulta también la posibilidad de alcanzar una adecuada autocomprensión de nuestra propia realidad (Sahlins, 1988a: 13 ss., 58-60 y 166-167).

La visión según la cual occidente habría emprendido un camino de modernización singular, realizado a través de la industralización y la generalización del capitalismo como expresión de unas dinámicas económicas distintivas, ha sido objeto de discusión. Algunos autores cuestionaron la idea asumida de que el tradicionalismo imperante en las sociedades no-occidentales actuaba como un freno a la modernización, debido a su rechazo hacia el individualismo y el materialismo. Como explicación alternativa, se sostenía que el avance occidental se basaba realmente en la explotación de las otras sociedades, generando una dependencia que impedía su desarrollo. La 
noción de sistema-mundo propuesta por Wallerstein y adoptada por otros autores, defendía la existencia de un sistema económico que funcionaba a nivel global a través de una división de funciones entre las diferentes regiones, establecidas desde el centro, hacia la periferia o la semiperiferia (Eades, 2005). Frank fue más allá en el cuestionamiento de la singularidad occidental, entendiendo su preeminencia actual como un episodio particular -oriente habría ejercido el predominio la mayor parte de la historia, que habría de entenderse dentro de unos procesos unificados y cíclicos. Así, la discontinuidad sería sólo aparente (Frank, 2009).

Sahlins critica la descripción que realizan los defensores del sistema-mundo sobre cómo se establecen las lógicas de dominación económica y cultural, pues asignarían a las sociedades periféricas un papel meramente pasivo que llevaría sin más a disolver sus culturas en el estilo de vida impuesto por el occidente capitalista. Estas sociedades, más bien, incorporan los principios, reglas y estilos propios del capitalismo de acuerdo a sus propios esquemas y valores culturales (Sahlins, 1988b).

Sahlins enfoca la posible resolución de la cuestión de la diferenciación occidental mediante la afirmación del carácter eminentemente simbólico del entramado institucional sobre el que se asienta cualquier sociedad, también una que se etiquete como moderna (Sahlins, 1988a: 60). De ahí que su crítica fundamental se dirija contra el predominio de una perspectiva netamente materialista y utilitarista a la hora de abordar el estudio de la cultura, desvelando cómo el influjo persistente de los prejuicios característicos de la cosmovisión occidental impide la posibilidad de alcanzar una comprensión plena de este fenómeno que, como resultado final, conlleva la confección de una imagen deformada de la realidad humana. Es así como la figura del homo economicus ha podido funcionar como medida universal para interpretar una acción social aislada del contexto cultural del que, paradójicamente, habría de obtener su sentido y razón de ser. De manera notoria, el comportamiento económico de las sociedades ajenas se vería oscurecido por la influencia de tales prejuicios (Sahlins, 2010: 9 ss. $)^{8}$.

Sahlins trata de invertir los términos de la relación: es el orden cultural el que concede su lugar y función a la economía, promoviendo para ello una configuración apropiada -en nuestro caso, la capitalista- (Sahlins, 1988a: 168). Por ello, cabe incluso poner en cuestión la pretendida autonomización de la economía impulsada por la modernidad, tal como había postulado Polanyi (Sahlins, 2015: 191). Pues tampoco las finalidades que alientan la actividad de la economía capitalista son autónomas respecto al orden cultural (Sahlins, 1988a: 164). Los procesos de producción y consumo en las sociedades modernas no dejan de obedecer, en el fondo, a una lógica significativa de clasificación y ordenación social (id.: Capítulo 4) ${ }^{9}$. El mercado, afirma Sahlins

${ }^{8}$ Los enfoques formalistas presentarían a las economías primitivas como simplemente subdesarrolladas, menos eficientes, respecto al modelo capitalista occidental. Por ello, propone un enfoque sustantivista, anclado en una consideración netamente cultural (Sahlins, 2010: 9$11)$.

${ }^{9}$ Sahlins trata de demostrar cómo la demanda de productos alimenticios y de vestido en Estados Unidos se articula según principios netamente culturales, dando lugar a una expresión peculiar de totemismo (Sahlins, 1988a:170-202). 
Repercusiones filosóficas de la crítica de Marshall Sahlins al arquetipo humano propugnado por la cosmovisión occidental

(2105: 192): "es una manera entre otras de convertir en objeto el orden histórico-cultural". Lejos de ser, por tanto, una entidad independiente y auto-constituida, es más bien el medio a través del cual se expresan adecuadamente una serie de valores culturales, es la realización institucional de una determinada cosmovisión. Aunque la conciencia de esa realidad quede oscurecida, precisamente, debido al peso del pensamiento utilitarista, que hace aparecer la realización de las necesidades materiales individuales como el principio constitutivo de la sociedad.

La propia cosmovisión occidental representaría simplemente una interpretación particular de la finitud humana, que de forma más amplia se dirige hacia lo que Sahlins denomina una "economía política de la alteridad". Pues las sociedades tienden a atribuir la fuente del valor de los objetos de consumo -así como la autoridad o su propia constitución- a un origen situado en un espacio exterior a la comunidad, que les confiere su carácter sagrado y su poder vivificador. (Sahlins, 2015: 194-216) ${ }^{10}$. Por tanto, tampoco en occidente la economía jugaría el papel determinante respecto a la ordenación del conjunto socio-cultural, pues sigue dependiendo del orden cultural al que sirve. Por ello, se trata de contemplar nuestra sociedad desde una perspectiva nítidamente antropológica que revele las lógicas simbólicas que subyacen e impulsan las reglas, la sintaxis general que moldea el modo de vida característico del occidente moderno orientando el funcionamiento de sus instituciones. Siguiendo así a autores como Baudrillard, Sahlins pretende superar la comprensión materialista que proscribe lo simbólico al nivel subordinado de la superestructura, para reivindicar el poder generador de esas lógicas simbólicas que conforman característicamente las prácticas sociales (Sahlins, 1988a: 166 ss.).

Tomando como referencia fundamental la lingüística de Saussure, Sahlins aboga por el carácter netamente arbitrario del símbolo como condición intrínseca de lo cultural. Es decir, su valor y función no dependen de ninguna correlación externa con algún ente o dimensión del mundo natural, sino de la relación que mantenga con otros signos, de su ubicación concreta en un contexto significativo determinado (id.: 44, 65$68,114$, y 197$)^{11}$. Es así que Sahlins se adhiere a una concepción de la cultura como un sistema simbólico complejo, en el que cada elemento adquiere su significación propia en relación al conjunto del que forma parte. Es por ello que los supuestos determinantes externos de la conducta y la organización social en realidad se integran en una sociedad determinada a través de la interpretación de los mismos que dicho sistema cultural promueve ${ }^{12}$. En ese sentido, la vocación materialista y utilitarista que

\footnotetext{
${ }^{10}$ Mauss había percibido que el valor material deriva de un poder trascendente, espiritual (Mauss, 2009).

${ }^{11}$ Cfr. Saussure (1990). Tal postura implicaría considerar que las acciones sociales, que revelan una cualidad perfomativa fundamental, obtienen su inteligibilidad de las estructuras culturales específicas situadas en el trasfondo. Cfr. Alexander y Mast (2006: 4).

${ }^{12}$ En este sentido cabría interpretar la acción social fundamentalmente como acción simbólica, tal como proponen Burke o Geertz. Se trataría de resaltar el carácter cultural de unas actividades que son expresivas antes que instrumentales, e irracionales antes que amoldadas en torno a una racionalidad estratégica, y que corresponden a un modelo de actuación dramatúrgica mejor que a una interacción económica. Cfr. Alexander y Mast (2006: 2).
} 
manifiesta la sociedad occidental, lejos de responder unívocamente a unos determinantes universales ineludibles, sería la expresión concreta de una cosmovisión peculiar, una interpretación significativa de la realidad sobre la cual se configura un modo de vida. Así, cabe entender que el modo de producción de bienes de consumo tal cómo se lleva a cabo en el contexto de la economía capitalista obedece, a la postre, a una lógica simbólica característica (id.: 178-202).

\section{BALANCE: UN MODELO HUMANO MÁS AJUSTADO}

Sahlins elabora una respuesta crítica a la concepción del ser humano y de la sociedad que atribuye a la cosmovisión típicamente occidental, alentando como respuesta la incorporación de dimensiones que habían sido relegadas en una definición que se revele más completa y ajustada. El desempeño de ese propósito presenta una serie de implicaciones que reclaman ser abordadas desde una reflexión netamente filosófica, atendiendo a su cariz ético-político fundamental, en tanto atañe a cuestiones relativas a la justicia. Pero se trataría así de emprender una senda que desborda el planteamiento y las pretensiones del autor, dejando quizá al descubierto algunas limitaciones. Pues se trata de un discurso que no pretende alcanzar un nivel de normatividad ni responde a pretensiones críticas, sino en todo caso aspira a elaborar una comprensión hermenéutica de la articulación institucional de la actividad cotidiana de las sociedades humanas.

Sahlins se caracterizaría por la defensa de una perspectiva netamente antropológica en la tarea de interpretar adecuadamente la realidad humana, tratando de evitar su subordinación a otro tipo de discursos que conduzcan hacia descripciones de tipo naturalista o materialista, reclamando en cambio la primacía y la autonomía de lo cultural. Así, postula el simbolismo como principio antropológico fundamental. De este modo, habría que considerar la capacidad simbólica como la condición definitoria de lo humano, cuya realización es fruto de una actividad eminentemente social. Sahlins se alinea, pues, con aquellos enfoques, como los desarrollados por Clifford Geertz o Mary Douglas, que conciben la antropología como un saber de tipo interpretativo que pretende esclarecer los significados contenidos en las diversas acciones sociales, promoviendo consecuentemente un concepto semiótico de la cultura ${ }^{13}$.

La esencia de lo cultural se hallaría, pues, en la dimensión simbólica, entendida como una cualidad inherente, no externa, y que se realiza como un proceso intersubjetivo de construcción de la realidad mediante el cual se produce la definición de las necesidades, las expectativas, y las finalidades que sean socialmente relevantes.

Este planteamiento se opone intrínsecamente a la idea de una naturaleza humana previa a la sociedad, tal como se hallaría en la base de la ideología liberal-burguesa, pues es justamente la dimensión social, constituida simbólicamente, la que configura la realidad humana, precediendo y dirigiendo la construcción de la individualidad. La definición del ser humano que resulte de la profundización en una perspectiva de este tipo, por tanto, permitiría incorporar dimensiones que habían sido relegadas por la

\footnotetext{
${ }^{13}$ Para Geertz la cultura consistiría en un sistema en interacción de signos interpretables, identificándose precisamente con el contexto que aporta la inteligibilidad a los fenómenos analizados (Geertz, 2003: 27).
} 
Repercusiones filosóficas de la crítica de Marshall Sahlins al arquetipo humano propugnado por la cosmovisión occidental

preeminencia de una concepción marcadamente individualista y biologicista. De este modo, Sahlins, remitiéndose a las nociones alternativas proporcionadas por otras culturas, postula una definición de lo humano más ceñida a su núcleo cultural que rehabilita plenamente la función de las disposiciones netamente sociales en el proceso de formación de la persona. En ese sentido, discute que la idea ampliamente difundida en el pensamiento occidental de que la socialización consista en una imposición coercitiva de unos patrones de comportamiento para encauzar y someter a las reglas de la sociedad lo que primariamente se revela como una naturaleza individual genuinamente asocial -prolongando la antigua oposición physis/nomos-. En la línea de otras investigaciones que denuncian esa visión descarnada de lo humano, la apertura a otras perspectivas culturales ayudaría a demostrar que la socialización consiste más bien en la realización progresiva de la tendencia a la sociabilidad y a una comprensión significativa del mundo con la que cuentan idiosincrásicamente los seres humanos (Sahlins, 2011: $111-123)^{14}$.

Este planteamiento resulta particularmente significativo, sin duda, en el momento actual, ya que cabe advertir la reactivación de un modelo nítidamente individualista, animado tanto desde las políticas que se están implementando desde diferentes instancias de poder, como en los nuevos discursos que están generándose desde ciertos ámbitos del saber -notoriamente, como se ha señalado, en las neurociencias-. Pues bien, resulta claro que las propuestas de Sahlins se alinean con aquellas investigaciones que tratan de contrarrestar la tendencia individualista insistiendo en la sociabilidad como constituyente esencial de la humanidad. Y en la medida en que permite revelar el carácter netamente ideológico y parcial que muestra la cosmovisión particular que sustenta dicha concepción individualista, cuestionando sus pretensiones universalistas, aporta un refuerzo apreciable a esa tarea de reivindicación de una comprensión alternativa, más rica, de lo humano.

No obstante, es preciso considerar si la propuesta antropológica de Sahlins está suficientemente fundamentada, abriendo el camino a la implementación de una perspectiva crítica, o si por contra, pueden quedar al descubierto ciertas carencias de su planteamiento. Si se trata de elaborar una definición consistente y constructiva del ser humano, es preciso estar guiado por una brújula moral que apunte hacia un horizonte crítico, pues no cabe conformarse con un planteamiento meramente descriptivo que corriera el riesgo, además, de resultar incompleto y parcial. En ese sentido, cabe observar, a mi juicio, que si bien la propuesta de Sahlins tiene el mérito de situar en primer plano las capacidades simbólicas y sociales como componentes fundamentales de lo humano, efectuando una crítica atinada del enfoque naturalista, parece no poder evitar en cambio la tendencia a quedar atrapado en una comprensión que a la postre se revele limitante, pudiendo desembocar en otra forma de determinismo, en este caso cultural. Pues, como advertía Aranguren, las ciencias sociales han promovido frecuentemente un sociologismo, que transmitía una percepción de lo moral restringida a la

\footnotetext{
${ }^{14}$ De Waal defiende la existencia de una potente tendencia a la sociabilidad en nuestros parientes primates -particularmente chimpancés o bonobos, más cercanos evolutivamente-, quienes exhiben ya en su comportamiento actitudes favorables al apaciguamiento o la cooperación, que surgirían también, de manera espontánea, en los niños pequeños. Cfr. Killen y de Waal (2000: 354 ss.) y Muñoz (2018).
} 
vigencia social, impidiendo captar ese carácter distintivo que reside en la libertad. La acción del ser humano puede ir más allá de las condiciones existentes, eligiendo consciente y responsablemente, cuestionando la bondad o justicia de las normas establecidas (Aranguren, 1998: 39-42).

El énfasis en el impulso generativo de lo cultural, considerado como una fuerza autónoma y auto-referencial, implica subestimar las posibilidades que tengan los individuos y los grupos para intervenir consciente y libremente en la elaboración de sus proyectos trascendiendo las constricciones culturales, así como en el devenir de la realidad social. Es decir, tal planteamiento no permite, a la postre, reconocerlos como sujetos activos de su propia historia, y sobre todo, ignora que los seres humanos pueden actuar autónomamente, como agentes morales. En definitiva, la hipostización de la categoría de lo cultural puede suponer la negación de una condición moral fundamental como es la libertad. Es por ello que considero que la caracterización del ser humano que propone Sahlins, aunque apreciable gracias a su énfasis en las capacidades simbólicas y sociales, debe ser afinada adoptando una perspectiva ética, subrayando la autonomía moral como elemento irrenunciable de la humanidad ${ }^{15}$. Propósito que podría afrontarse, a mi juicio, siguiendo las propuestas de la ética del discurso renovada, desarrollada en la Escuela de Valencia, que partiendo del marco de la ética discursiva, pretende aplicar sus principios a los contextos reales y específicos de acción. De este modo, se trata de situar el momento universal e incondicionado encarnado en un la idea de un diálogo simétrico constituido por todos los afectados por una norma, en las situaciones sociales donde se desarrollan las prácticas concretas, desarrollando las distintas éticas aplicadas (Calvo, 2012: 98-102).

La adopción de un punto de vista genuinamente moral incita a distinguir entre el ser y el deber ser, o lo vigente socialmente de lo válido. Insistir en la autonomía y la capacidad explicativa de la lógica cultural puede suponer una mera aceptación de las configuraciones institucionales existentes consideradas como el inequívoco resultado de los procesos subyacentes. Si bien una aproximación más hermenéutica como la de Sahlins abre la puerta a una lectura interpretativa perspicaz sobre la peculiaridad de la cosmovisión y el modo de vida occidental, sigue careciendo del soporte que aportaría un maro crítico desde el que poder juzgar la justicia o la validez moral contenida en las diferentes instituciones, normas, prácticas o costumbres estudiadas por la etnografía. Pero es necesario alcanzar una comprensión que trascienda la limitación de la particularidad empíricamente manifestada, abriéndose al horizonte de la universalidad.

Por ello, considero oportuno recurrir al marco teórico proporcionado por la hermenéutica crítica, que atiende a las prácticas reales y concretas tratando de comprender su sentido dentro del contexto en el que se realizan, sin renunciar a la posibilidad de revelar la tendencia a la universalidad que subyace a las mismas, incorporando así el momento kantiano de incondicionalidad que aporta el necesario refuerzo normativo

\footnotetext{
${ }^{15}$ Se entiende la autonomía fundamentalmente en su sentido kantiano, es decir, como la capacidad autolegislativa de los sujetos racionales, que permite trascender el estado de heteronomía, de dependencia respecto a normas externas a la propia razón. Cfr. Conill (2013: 5).
} 
Repercusiones filosóficas de la crítica de Marshall Sahlins al arquetipo humano propugnado por la cosmovisión occidental

y crítico característico de la reflexión moral (Conill, 2006: 203-214 y 271-280) ${ }^{16}$. Es decir, se trata de sostener una perspectiva crítica ante las variadas experiencias y realidades sociales e institucionales, que permite evaluar la justicia y corrección de las mismas, pero interpretándolas dentro de su propio marco de inteligibilidad.

\section{BIBLIOGRAFÍA}

ANDERSON, Elizabeth. (2000). "Beyond Homo economicus: New Developments in Theories of Social Norms". Philosophy \& Public Affairs, 29 (2), pp. 170-200.

ALEXANDER, Jeffrey y MAST, Jason. (2006). "Introduction: symbolic action in theory and practice: the cultural pragmatics of symbolic action", en ALEXANDER, Jeffrey, GIESEN, Bernard y MAST, Jason L. (eds.). (2006). Social Perfomance: Symbolic Action, Cultural Pragmatics, and Ritual. Cambridge: Cambridge University.

APPLBAUM, Kalman (1998). "The Sweetness of Salvation". Current Anthropology, 39 (3), pp. 323-350.

MUÑOZ, Albert (2014). La construcción del carácter frente a las contradicciones del Nuevo Capitalismo en Richard Sennett. (Tesis doctoral).

MUÑOZ, Albert (2018). "La cuestión del origen evolutivo de la moral en el primatólogo Frans de Waal “. Thémata, 57, pp. 49-68.

MUÑOZ, Albert (en prensa). "El fomento de un modelo humano limitado en el nuevo capitalismo", en GONZALEZ ESTEBAN, Elsa et al. (Eds.). Ética y democracia. Desde la razón cordial. Granada: Comares.

CALVO, Patrici. (2012). Racionalidad económica: aspectos éticos de la reciprocidad. (Tesis doctoral).

CARRIER, James G. (2005). "Introduction", en en CARRIER, James G. (ed.). $A$ Handbook of Economic Anthropology (2005). Northampton: Edward Elgar Publishing.

CONILL, Jesús. (2004). Horizontes de economía ética. Madrid: Tecnos.

CONILL, Jesús. (2006). Ética hermenéutica. Madrid: Tecnos.

\footnotetext{
${ }^{16}$ Se trata así de una razón que trata de superar las limitaciones del mero procedimentalismo y el formalismo para abrirse a la variedad de la experiencia.
} 
CONILL, Jesús. (2013). “La invención de la autonomía”. Eidon, 39, pp. 2-12.

CORTINA, Adela. (2010). "Neuroética: ¿Las bases cerebrales de una ética universal con relevancia política?". Isegoría, 42, pp. 129-148.

CROUCH, Peter. (2005). "Models of Capitalism". New Political Economy, 10 (4), pp. 439-456.

DAWKINS, Richard. (2002). El gen egoísta. Barcelona: Salvat.

DUMONT, Louis. (1999). Homo aequalis. Génesis y apogeo de la ideologŕa económica. Madrid: Taurus. [Versión original 1977].

EADES, Jeremy S. (2005). "Anthropology, political economy and world-system theory", en CARRIER, James G. (ed.). A Handbook of Economic Anthropology. (2005).

Northampton: Edward Elgar Publishing.

FEHR, Ernst y FISBACHER, Urs. (2003). "The nature of human altruism". Nature, 425, pp. 785-791.

FRANK, André G. (2009). "ReOriente. Economía global en la Era Asiática. Conclusiones historiográficas e implicaciones teóricas". CyE 2, pp. 95-140.

GEERTZ, Clifford. (2003). La interpretación de las culturas. Barcelona: Gedisa. [Versión original 1973]

GIDDENS, Anthony. (1992). El capitalismo y la moderna teoría social. Barcelona. Labor.

GOWDY, Jack. (2006). "Business Ethics and the Death of 'Homo Economicus", en ZOLNAI, Lázsló e IMS, Knut. J. (eds.). Business Within Limits. Oxford: Peter Lang.

HARTMANN, Martin. (2012). "Against First Nature. Critical Theory and Neuroscience", en CHOUDORY, Suparma y SLABY, Jan (eds.). (2012). Critical Neuroscience: A Handbook of the Social and Cultural Contexts of Neuroscience. Oxford: Blackwell.

ISAAC, Barry L. (2005). "Karl Polany", en CARRIER, James G. (ed.). A Handbook of Economic Anthropology. (2005). Northampton: Edward Elgar Publishing.

KILLEN, Melanie y DE WAAL, Frans. (2000). "The Evolution and Development of 
Repercusiones filosóficas de la crítica de Marshall Sahlins al arquetipo humano propugnado por la cosmovisión occidental

Morality", en AURELI, Filippo y DE WAAL, Frans (eds.). (2000). Natural conflict resolution. Berkeley: University of California Press.

LIE, John. (1991). "Embedding Polanyi’s Market Society". Sociologial Perspectives, 34 (2), pp. 219-235.

MAUSS, Marcel. (2012). Ensayo sobre el don. Forma y función del intercambio en las sociedades arcaicas. Madrid: Katz. [Versión original 1924].

MCPHERSON, C.B. (2005). La teoría política del individualismo posesivo. De Hobbes a Locke. Madrid: Trotta. [Versión original 1962].

ORTIZ, Sutti. (2005). "Decisions and choices: the rationality of economic actors", en CARRIER, James G. (ed.). (2005). A Handbook of Economic Anthropology. Northampton: Edward Elgar Publishing.

POLANY, Karl. (2015). La gran transformación. Los orígenes políticos y económicosde nuestro tiempo. México: F.C.E. [Versión original 1944].

SAHLINS, Marshal. (1988a). Cultura y razón práctica. Barcelona: Gedisa. [Versión original 1976]

SAHLINS, Marshal. (1988b). "Cosmologies of capitalism: the trans-pacific sector of the 'world-system". Proceedings of the British Academy, 74, pp. 1-51.

SAHLINS, Marshal. (2010). Economía de la edad de piedra. Madrid: Akal.[Versión original 1974]

SAHLINS, Marshal. (1990). Uso y abuso de la biologra. Madrid: Siglo XXI.[Versión original 1976]

SAHLINS, Marshal. (1996). "The Sadness of Sweetness. The Native Anthropology of Western Cosmology". Current Anthropology, 37 (3), pp. 395-428.

SAHLINS, Marshal. (2011). La ilusión occidental de la naturaleza humana. México: FCE.

SAHLINS, Marshal. (2015). "Sobre la cultura del valor material y la cosmografía de la riqueza". Etnografías contemporáneas, 1 (1), pp. 181-226.

SAUSSURE, Ferdinand de. (1990). Curso de lingüistica general. Madrid: Alianza. [Versión original 1916] 
SEN, Amartya. (1977). "Rational Fools: A critique of the Behavorial Foundations of Economic Theory". Philosophy \& Public Affairs, 6 (4), pp. 317-344.

WEBER, Max. (2001). La ética protestante y el espíritu del capitalismo. Madrid: Alianza. [Versión original 1905]

WILSON, Edward O. (1980). Sociobiología: la nueva síntesis. Barcelona: Omega.

WILSON, Edward O. (2012). La conquista social de la tierra. Barcelona: Debolsillo. 